\title{
El Maestro Sanín Cano
}

\section{(Recuerdos)}

Supe de Sanín Cano, el maestro a quien consagra este justo ho$\$$ menaje la Revista Iberoamericana, supe de sus condiciones humanas, del excepcional valor de su carácter, ya que el ensayista, el crítico, el humanista moderno que alientan en el colombiano universal me eran familiares desde mis días adolescentes, cuando José de Armas y Cárdenas, un discípulo cubano de Menéndez y Pelayo, me habló en una bellísima carta del autor de La civilización manual y me decía estas palabras que creo recordar textualmente: "me habla usted del caudaloso saber y de la penetración crítica de don Baldomero Sanín Cano, y yo convengo en ello, pero además debe ser varón austerísimo, de altas virtudes morales, porque Gabriel de Zéndegui no acaba de ponderarme la actitud ética del gran escritor, y Zéndegui es un santo".

$\mathrm{Y}$ ha sido precisamente con motivo de Justo de Lara (pseudónimo de José de Armas), como volví no ha muchos meses a tener noticias directas del maestro colombiano. Le remití un Cuaderno de Cultura que recogía el estudio de nuestro humanista titulado "Cervantes y el Quijote". Es un sagaz ensayo, cuya primera edición es de 1905. Ante su lectura recordó Sanín Cano sus viejas devociones cervantinas. Hace años tradujo del inglés a nuestra lengua la biografía de Cervantes escrita por el ilustre hispanista J. FitzmauriceKelly. ¿Qué ve el maestro colombiano en el estudio cervantista de Justo de Lara? No se fija en lo literario tan sólo. Así comienza por señalar, como una de sus notas distintivas, "una bondad inagotable apoyada en un firme sentido de la equidad y en una capacidad finísima de valoración". $Y$ añade luego: "además una feliz pureza de 
expresión y un gusto severo servido por un conocimiento vastisimo de las buenas letras en más de cuatro idiomas".

Obsérvese cómo queda precisada en estas líneas la aspiración universalista del crítico cubano. La parte final de su estudio es un ensayo admirable de literaturas comparadas. Por eso alude Sanín $\mathrm{Ca}-$ no, muy certeramente, a esa vastísima lección de buenas letras en más de cuatro idiomas.

Escribe su deliciosa carta el autor de La civilización manual desde Popayán. No conozco la ciudad, famosa en los fastos de la poesía, pero la he vivido en la obra de Guillermo Valencia. Al gran poeta alude su amigo entrañable en la forma más delicada: "Recluido en esta ciudad por la edad y por el clima ideal no menos que por el recuerdo de un amigo incomparable, a cuyo lado pasé los cuatro años últimos de su vida, vivo de recuerdos." Hay un acento melancólico, una vaga nostalgia, en estas palabras del maestro. ¡ Cuántas cosas despiertan en el espíritu ante la alusión al poeta de "Anarkos"! :Qué ejemplo el de la honda amistad del crítico de amplias proyecciones y el maestro de la poesía! Valencia, candidato dos veces a la presidencia de su país por el partido conservador, encarnaba tradiciones políticas que tuvieron siempre, en Sanín Cano, a un opositor tenaz. Es muy significativo que el poeta Valencia, hombre de derechas, haya encontrado su más alto crítico en Sanín Cano, una gran figura de la tradición liberal. Valencia es ese amigo incomparable, a que aluden las melancólicas palabras del maestro. "Su recuerdo", tanto o más que el clima suavísimo, retiene al ensayista en esa vieja ciudad llena aún de las clásicas notas de su cantor majestuoso.

He revivido episodios de esta fraternal amistad, algunos de los cuales tuve el privilegio de oír relatar al propio Sanín Cano. Iluminan un período de profunda renovación literaria. Expresan su verdadero espíritu, más que copiosos repertorios documentales. Quiero recordar ahora uno de los más reveladores.

En los días de la coronación de Jorge $V$, coincide Sanín Cano en Londres con su viejo amigo don Emilio Bobadilla, el injustamente olvidado Fray Candil. Mientras esperan en una terraza el comienzo de una ceremonia oficial, se ha acercado a su mesa otro periodista, residente en la capital inglesa desde hacía años: Ramiro de Maeztu. Pondera el insigne escritor español sus ultimas lectu- 
ras de poetas alemanes. "Había ido a Alemania para aprender qué cosa era la poesía lírica de la época moderna, leyendo a Hofmansthal, a Stefan George... Bobadilla parecía convencido. Lo estaba tan sinceramente que observó con un dulce reproche: tienes razón, sólo que has ido muy lejos y demasiado tarde a adquirir ese conocimiento. Tuve ocasión de leer a estos poetas en Bogotá, en 1897, en las versiones transparentes que de ellos hizo Guillermo Valencia."

Recojo la anécdota, que le oí cantar al propio Sanín Cano, de uno de sus ensayos: el dedicado a Emilio Bobadilla, en los días de la muerte de nuestro compatriota, y reproducido en el libro Indagaciones e imágenes (Bogotá, 1931). No cuenta el autor que él inició a Valencia en esta fase de la poesía alemana.

En la fecha a que alude Fray Candil, el grupo literario, que tenía en Sanín Cano su crítico orientador y en Valencia su altísimo poeta, libraba encendidas controversias con las más interesantes figuras literarias, $y$ ha tenido en don Luis María Mora su historiador erudito y apasionado. Con no disimulada propensión libresca se denominaba a esta capilla La Gruta Simbólica, y el libro, que ha referido puntualmente sus peripecias, se titula Los contertulios de la Gruta Simbólica.

Es muy interesante que en las agrias páginas que dedica don Luis María Mora a don Baldomero se señale como una limitación, o un exceso, en la obra del gran crítico una actitud que es precisamente la afirmación cumplida de su universalidad, de su proyección vastísima. Decía el desenfadado don Luis "que a duras penas sabemos por estas latitudes un poco de francés y algo de inglés comercial y tardará mucho todavía antes que podamos, como Sanín Cano, pasearnos de bracete con los grandes maestros suecos, daneses, o noruegos, con los cuales él se trata de tú por tú". Ejemplo admirable de autodidactismo, Sanín Cano aprendió en Bogotá el danés para conocer directamente a Brandes, el crítico de Las grandes corrientes literarias del siglo XIX; el noruego, para acercarse sin trabas a la obra ibseniana; el alemán... Un poligloto le llama con desdén un poco singular el buen don Luis María... Pero las lenguas vivas, como las muertas, han sido para el maestro colombiano, antes que nada, instrumentos de cultura. Por eso, en el duro aprendizaje había esa alegría que sólo sentimos ante una nueva conquista 
del espíritu. Con razón ha dicho el doctor Germán Arciniegas, en un fino ensayo sobre Sanín Cano, que el maestro, en su infatigable tarea nos da siempre el ejemplo de su júbilo, lleno de serenidad.

La obra de Sanín Cano recogida en volúmenes es una mínima parte de la que está dispersa en publicaciones del más diverso linaje. Samper Ortega, en la Biblioteca Aldeana, en el tomo que dedica a los eruditos antioqueños, el 54 de la colección (el término erudito expresa muy limitadamente lo que es la obra de un ensayista creador como Sanín Cano), dice que nuestro autor "era un ilustre desconocido" para la nueva generación colombiana, cuando llegó a su patria después de largos años de residencia en Europa. Sin embargo, su magisterio ha ejercido una profunda influencia. No porque haya enseñado directamente - fué sólo por algún tiempo lector en la Universidad de Edimburgo- "sino por lo que ha estudiado", para recordar la expresión de Arciniegas. Dice el autor de Los alemanes en América, una de las más bellas y sugestivas monografías históricas de estos tiempos, que hay catedráticos que dicen: "1levo 50 años de enseñar". Querríamos preguntarles: ¿Y han tenido alguno de estudio? Si a Sanín Cano le preguntásemos:-Díganos, maestro: ¿cuántos años lleva de enseñar?, quizá diría:-Ninguno. Pero llevo sesenta de estudiar.

Estas palabras se escriben en 1940. Hoy son muchos más años de estudio persistente, de la persistente visión universal sobre los hombres, las ideas y los hechos. Hace algún tiempo un joven escritor cubano, profesor de literatura hispanoamericana en la Universidad de California, el doctor Manuel Pedro González, tuvo una justa y feliz iniciativa, en uno de los periódicos Congresos de Literatura Iberoamericana, que se celebraban antes de la guerra: la de un homenaje continental a Sanín Cano. Se le dirigió un mensaje al Presidente de Colombia, que a la sazón lo era un periodista insigne, el doctor Eduardo Santos. El mensaje, calzado por más de cien firmas - yo me honré en firmarlo-, proponía una edición nacional de las obras de Sanín Cano y un volumen con los trabajos escritos sobre el maestro. Nada se ha hecho hasta ahora. Sanín Cano vive en su actividad infatigable de siempre. Hace poco más de dos años dió a la colección de Tierra Firme (México), un voltumen sobre las letras colombianas, que es un ejemplo de síntesis crítica, ponderada y sabia. 
En 1935 publicó la Dirección de Cultura del Ministerio de Educación (un departamento oficial ctyas tareas tuve el honor de inaugurar) el Homenaje a Enrique José Varona, en el primer cincuentenario de su primer curso de filosofía (1880-1930), valiosísima miscelánea de estudios literarios, históricos y filosóficos. Hay allí unas páginas reveladoras del maestro Sanín Cano, fechadas en Santa Fe de Bogotá, en julio de 1932. Aún vivía el maestro cubano a quien se consagraba el libro. El escritor colombiano evoca su aprendizaje literario. Corría el año de 1887 "y comenzaba a rehacer fervorosamente - nos dice en ese artículo de sabor autobiográficomi educación literaria y filosófica". Un cubano ilustre, que tuvo en Colombia su segunda patria, don Rafael María Merchán, le llamó para que hiciera el índice de su biblioteca, de unos diez o doce mil volúmenes. Había revistas, muchas revistas, francesas, italianas, alemanas; las más eran en español y algunas procedían de Cuba. Allí conoció el maestro la Revista de Cuba, fundada por don José Antonio Cortina, "allí dieron mis ojos - nos cuenta- con el nombre hoy para mí sagrado de Enrique José Varona".

Sentía el escritor una profunda crisis de conciencia. Necesitaba volver a estudiar, "no sin haber desaprendido la mayor parte de lo que hasta alli había creído saber". Debía rectificar nociones falsas adquiridas en las aulas, redondear otras incompletas. En ese momento grave llegó a sus manos la obra de Varona. El maestro cubano le enseñó "los primeros rudimentos de probidad intelectual". Parecía que sus libros daban al lector apasionado un consejo que nunca ha olvidado nuestro escritor: "importa como paso principal trazar la linea divisoria entre lo que sabemos y lo que ignoramos". Nos hace luego Sanín Cano esta confesión: "Al tratar entonces de fijar las sinuosidades de esta línea me dí cuenta, un poco demasiado tarde, de que al lado de nociones elementales muiy estrechas se desenvolvía el desierto para mí inexplorado de lo que ya debiera saber..."

¿Cuánta gratitud siente por Varona el maestro de Colombia! El artista que alienta en el filósofo de los Cursos libres le fascina. He aquí cómo ve un breve volumen de versos publicado por Varona con el pseudónimo de Luis del Valle. "Un pensamiento delicado, clásico, finamente expresado, formaba el sentido de líneas armonio- 
sas... La fase era una cosa espiritual y trascendente como en Matthew Arnold... Era una poesía destinada a pasar inadvertida de muchos y a llenar con deleites imprevistos las horas del pensador reconcentrado."

Más tarde hace Sanín Cano el elogio de Desde mi Belvedere. Advierte agudamente que cuando la prosa castellana corría el peligro de eterizarse entre los deliquios de escritores a quienes importaba más la riqueza y vanidad del adjetivo que la arquitectura general de la sentencia y su acuerdo con el pensamiento, aparecía este libro en que el estilo es una cosa sutil, puramente espiritual, inasible, y sin embargo, presente como los besos que dijo Tennyson: "recordados después de la muerte".

Como hemos dicho escribe esas páginas Sanín Cano en 1932. Dos años más tarde, cuando le dí cuenta de que al fin iba a publicarse el homenaje a Varona, me escribió contándome cuán tarde supo la muerte del gran escritor cubano. El trasatlántico en que hacía no sé que largo viaje, podía comunicar al pasaje las que juzgaba las noticias esenciales: un encuentro pugilístico, las últimas cotizaciones de la bolsa, los recientes acontecimientos políticos de este país o de aquel otro. La muerte de un hombre como don Enrique José Varona no parecía tener importancia alguna y no se dió la noticia. Por eso vino a conocerla tardíamente el maestro colombiano que confiesa, con su sinceridad característica, deber tanto al maestro de Cuba. Sanín Cano deducía del hecho una tácita condenación de la civilización maquinista de nuestro tiempo.

Una vez en Madrid, en la humilde morada de un estudioso, nos reunimos unos cuantos amigos para oír por primera vez la interpretación, bajo la experta dirección del musicólogo y folklorista don Eduardo M. Torner, de la música de algunas cantigas de Alfonso el Sabio. Estábamos Alfonso Reyes, Díez-Canedo, Eugenio d'Ors, y desde luego, Baldomero Sanín Cano. ¿ No recuerda, maestro y amigo, aquella velada de música en la primavera madrileña? No nos atrevíamos a hablar para no alejar demasiado pronto de nuestro alrededor el encanto de aquella hora. De todos, quizá el más silencioso fué el maestro Sanín Cano. A las pocas semanas me habló el escritor de las impresiones de aquella noche. Vi cómo aquella música del siglo xiıI vivía en el corazón del maestro. El ritmo de silencio penetrante le había unido con más intimidad a su espíritu. 
Evoco este recuerdo de silencio, de paz y de música casi inefable, en el homenaje que hoy rinde a Sanín Cano, bajo la égida de Manuel Pedro González, el ilustre profesor de la Universidad de California, un grupo de amigos de la cultura americana.

José María Chacón y Calvo 
